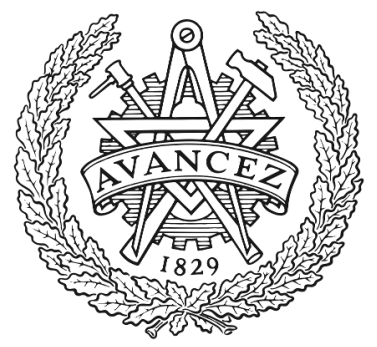

CHALMERS

UNIVERSITY OF TECHNOLOGY

\title{
Corporate distribution networks for slot array antenna based on groove gap waveguide technology
}

Downloaded from: https://research.chalmers.se, 2023-04-26 09:52 UTC

Citation for the original published paper (version of record):

Farahbakhsh, A., Zarifi, D., Uz Zaman, A. et al (2016). Corporate distribution networks for slot array antenna based on groove gap waveguide technology. 10th European Conference on Antennas and Propagation, EuCAP 2016, Davos, Switzerland, 10-15 April 2016: Art. no. 7481157-. http://dx.doi.org/10.1109/EuCAP.2016.7481157

N.B. When citing this work, cite the original published paper. 


\title{
Corporate Distribution Networks for Slot Array Antenna Based on Groove Gap Waveguide Technology
}

\author{
A. Farahbakhsh ${ }^{1}$, D. Zarifi ${ }^{2}$, A. U. Zaman ${ }^{3}$, P. -S. Kildal ${ }^{4}$ \\ ${ }^{1}$ Graduate University of Advanced Technology, Kerman, Iran, alifa@chalmers.se \\ ${ }^{2}$ University of Kashan, Kashan, Iran, zarifi@chalmers.se \\ ${ }^{3}$ Chalmers University of Technology, Göteborg, Sweden, zaman@chalmers.se \\ ${ }^{4}$ Chalmers University of Technology, Göteborg, Sweden, per-simon.kildal@chalmers.se
}

\begin{abstract}
This paper deals with the design of low loss wideband power dividers based on groove gap waveguide (GGW) technology. The advantages of GGW power dividers are low insertion loss, high power handling capacities, ease of fabrication and compatibility with integrated microwave networks. A 64-way power divider is designed and used as the feeding network of a $16 \times 16$-element slot antenna array at 60 $\mathrm{GHz}$ band. The results show that the gain and total radiation efficiency of the antenna are more than $32.5 \mathrm{dBi}$ and $90 \%$ over the desired frequency range from 56 to $66.4 \mathrm{GHz}$.
\end{abstract}

Index Terms - corporate feeding network, groove waveguide technology, slot antenna array.

\section{INTRODUCTION}

Power dividers are building blocks of many microwave and millimeter-wave components and networks. Especially in microwave and millimeter-wave integrated circuits, the feeding system of an array antenna needs a power divider with low loss, high Q-factor and broad bandwidth. The conventional rectangular waveguide power divider can meet these requirements. For instance, power dividers fabricated from traditional waveguides have the advantages of low insertion loss and high power handling capacities, but their large size and high cost is a limiting factor.

In this contribution, the aim of the present work is to utilize groove gap waveguide (GGW) technology to design of power dividers for use in feeding networks of large slot antenna arrays. The gap waveguide technology was introduced in [1-3]. The advantage compared to microstrip and Substrate Integrated Waveguide (SIW) technologies is that this gap waveguide technology can keep a planar profile as well as being low loss [4-6]. In addition, this technology can be realized without good metal contacts between the different layers of multilayer structures. There are also many modern manufacturing technologies that will suit such planar surfaces with texture, such as die sink Electrical Discharge Manufacturing (EDM), Electron Beam Melting (EBM), multilayer die pressing, and 3D screen printing. Therefore, the gap waveguide technology has a large potential for millimeter wave applications.

To date, some array antennas have been realized based on gap waveguide distribution networks: a 4x1 slot array fed by

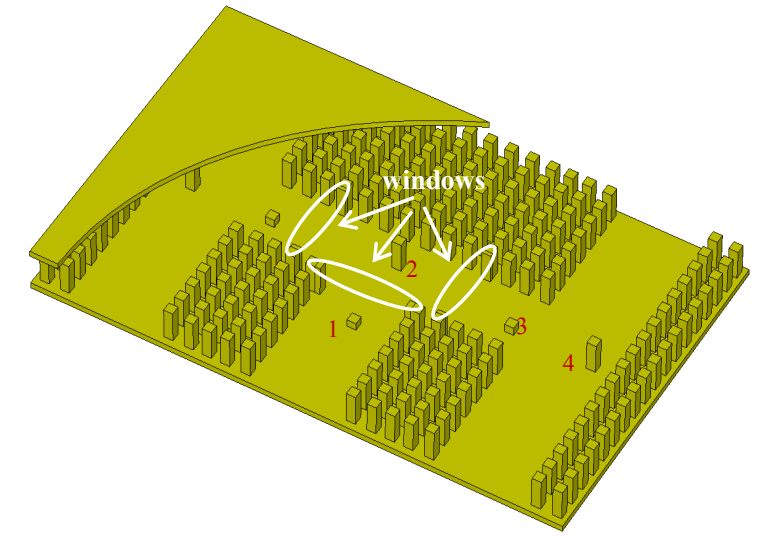

Fig. 1. The geometry of 4-way H-shaped GGW power divider.

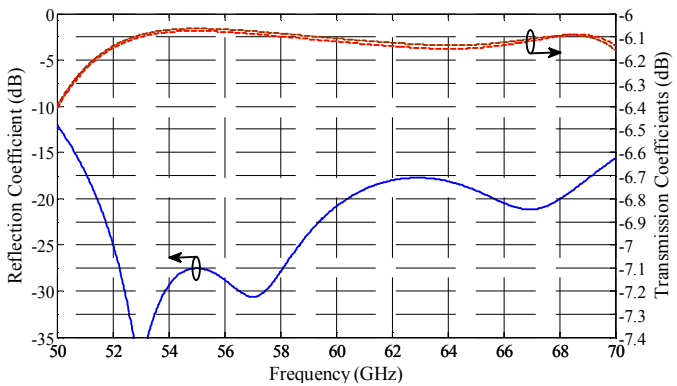

(a)

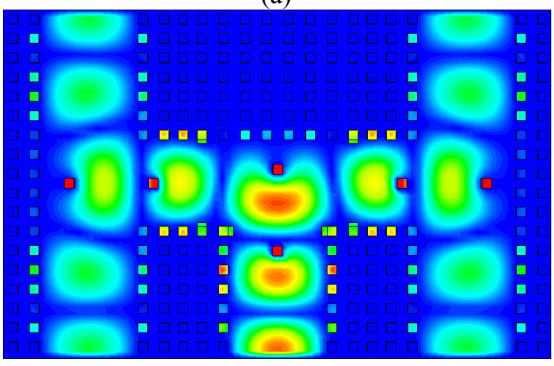

(b)

Fig. 2. (a) Simulation results for amplitudes of reflection and transmission coefficients. (b) Electric field distribution at frequency $60 \mathrm{GHz}$.

ridge gap waveguide [7], a $4 \times 4$ horn array at $15 \mathrm{GHz}$ fed by inverted microstrip gap waveguide in [8], and a $4 \times 4$ slot array at $60 \mathrm{GHz}$ fed by microstrip-ridge gap waveguide [9]. In 
TABLE I. Design PARAMETERS OF 4-WAy GGW POWER DiviDER

\begin{tabular}{ccc}
\hline \hline Component & Parameter & Value (mm) \\
\hline \multirow{2}{*}{ Vertical Grooves } & width & 4.2 \\
& height & 1.35 \\
Horizontal Grooves & width & 3.6 \\
& height & 1.35 \\
Window 1 & width & 3.72 \\
& distance to junction & 0.0 \\
Windows 2 \& 3 & width & 3.29 \\
& distance to junction & 2.5 \\
Pin 1 & height & 0.31 \\
& distance to junction & 0.81 \\
Pin 2 & height & 1.3 \\
& distance to wall & 1.42 \\
Pin 3 & height & 0.36 \\
& distance to junction & 0.43 \\
Pin 4 & height & 1.3 \\
& distance to wall & 1.47 \\
\hline \hline
\end{tabular}

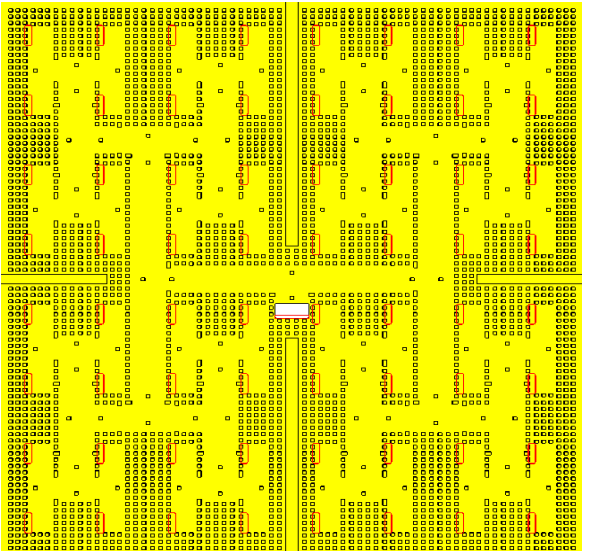

(a)

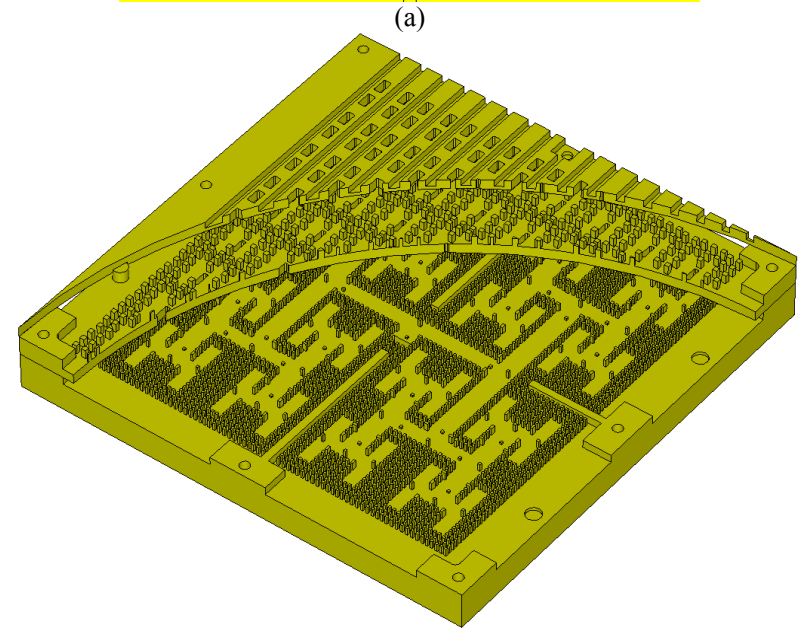

(b)

Fig. 3. (a) Configuration of designed feeding network. (b) Configuration of complete $16 \times 16$-element slot antenna array.

addition, recently, the use of gap waveguide distribution networks for design of W-band $8 \times 8$ slot arrays has been reported in $[10,11]$.

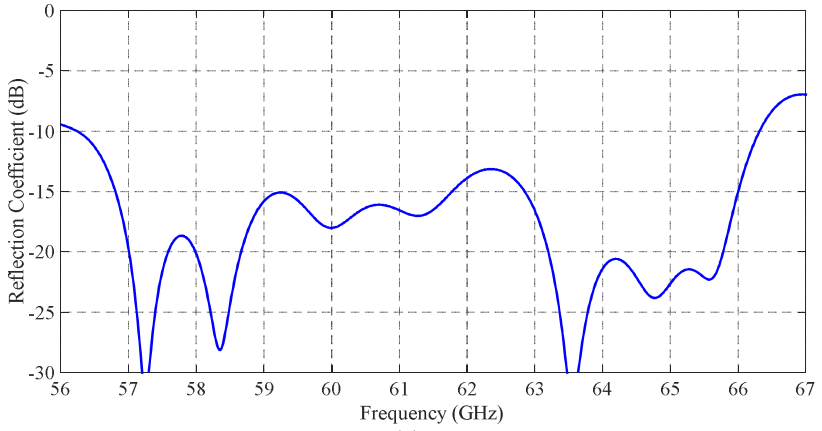

(a)

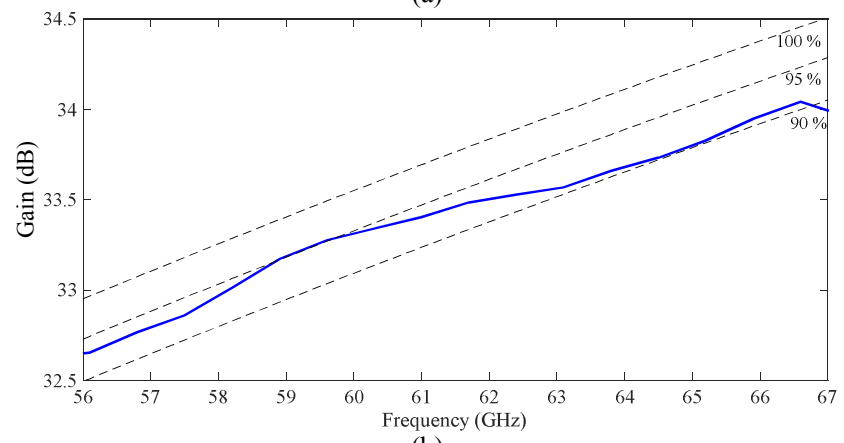

(b)

Fig. 4. (a) Simulated $\left|S_{11}\right|$ and (b) simulated gain of $16 \times 16$-element array.

The current paper presents a 16x16 slot array antenna fed by groove gap waveguide distribution network.

\section{GGW POWER DIVIDER}

\section{A. 4-Way GGW Power Divider}

A physically symmetric H-shaped 4-way power divider with equal-phase and amplitude based on GGW is shown in Fig. 1. The required power-split ratio and impedance matching are achieved by fine tuning the position and height of some matching pins and position and widths of windows. The optimized values of the dimensions of structure are given in Table I. Simulation results shown in Fig. 2 reveal that power divider can achieve stable power distribution in the bandwidth from $51 \mathrm{GHz}$ to $70 \mathrm{GHz}$ with a return loss better than $15 \mathrm{~dB}$. This is a relative bandwidth of 1.37 which is larger than in any previous works on similar slot arrays with different waveguide technologies.

\section{B. 64-way GGW Power Divider As Feeding Network of $A$ Slot antenna Array}

It is common practice to design multi-way power dividers by interconnecting small power dividers. Here, a 64-way GGW power divider is realized by interconnecting predesigned 4-way power dividers, as shown in Fig. 3 (a). This power divider is deployed to feed a $16 \times 16$-element slot antenna array, as shown in Fig. 3(b). The input power equally divided into 64 portions and then has been coupled to the cavity layer with the assistance of the coupling slots. The distances between the coupling slots are chosen to be 8 and 8.8 $\mathrm{mm}$ along the $\mathrm{x}$ - and $\mathrm{y}$-axis, respectively. 


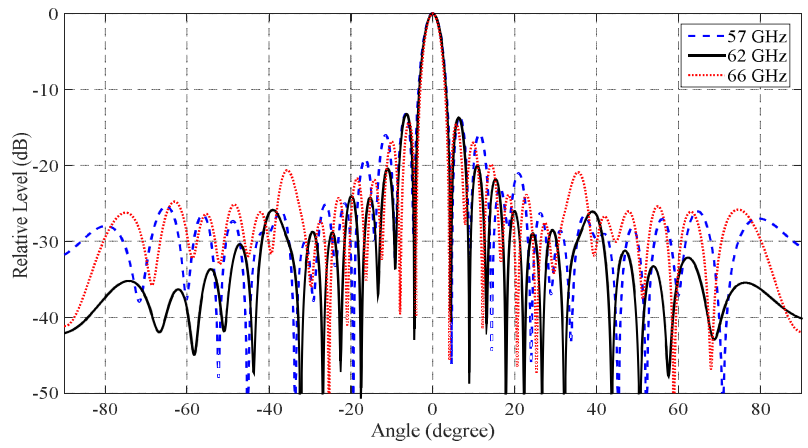

(a)

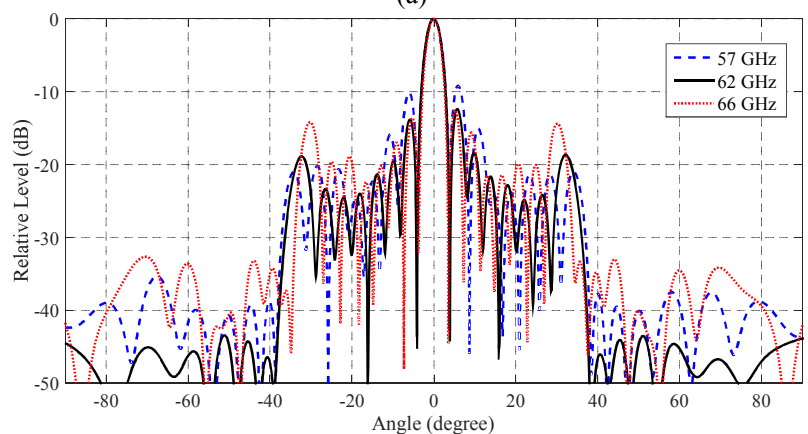

(b)

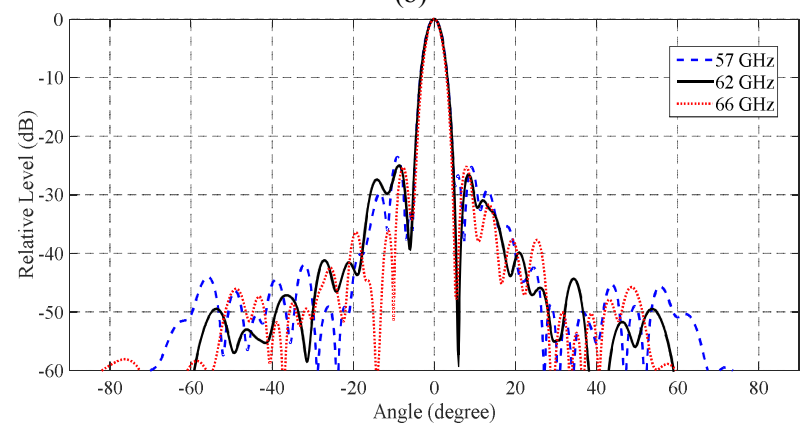

(c)

Fig. 5. Simulated radiation patterns of the designed $16 \times 16$-element array. (a) $\varphi=0^{\circ}$. (b) $\varphi=90^{\circ}$. (c) $\varphi=45^{\circ}$-plane.

\section{Simulation RESUlts}

Fig. 4(a) depicts the simulated reflection coefficient of the complete antenna. Observe that the designed antenna exhibits an impedance bandwidth (SWR $\leq 2)$ of $17 \%$ from 56 to 66.4 $\mathrm{GHz}$ Also, the simulated frequency characteristics of the directivity and realized gain of the antenna is shown in Fig. 4(b). Observe that the obtained gain is more than $32.5 \mathrm{dBi}$ with a simulated efficiency higher than $90 \%$, i.e. $-0.5 \mathrm{~dB}$, including conductive losses.
The simulated radiation patterns of antenna at 57,62 and $66 \mathrm{GHz}$ in both the E- and H-planes and also 45-plane are shown in Fig. 5. Observe that the first sidelobe levels in both E- and H-planes are around $-13 \mathrm{~dB}$. Also, the side lobe level of the designed array in the $45^{\circ}$-plane is below $-25 \mathrm{~dB}$ over the desired frequency band.

\section{ACKNOWLEDGMENTS}

The work has been supported by the European Research Council (ERC) via an advanced investigator grant ERC-2012ADG 20120216, and by a project within the VINNOVA funded Chase Antenna Systems excellence center at Chalmers.

\section{REFERNCES}

[1] P.-S. Kildal, E. Alfonso, A. Valero-Nogueira, and E. Rajo-Iglesias, "Local metamaterial-based waveguides in gaps between parallel metal plates," IEEE AntennasWireless Propag. Lett., vol. 8, pp. 84-87, 2009.

[2] P.-S. Kildal, "Three metamaterial-based gap waveguides between parallel metal plates for mm/submm waves," in Proc. 3rd Eur. Conf. Antennas Propag., Berlin, Mar. 2009.

[3] E. Pucci, A. U. Zaman, E. Rajo-Iglesias, P.-S. Kildal, and A. Kishk, "Study of Q factors of ridge and groove gap waveguide resonator," IEEE Trans. Compon., Packag. Manuf. Technol., vol. 7, no. 11, pp. 900908, November 2013.

[4] X. Xu, R. G. Bosisio, and K. Wu, "A new six-port junction based on substrate integrated waveguide technology," IEEE Transactions on Microwave Theory and Techniques, vol. 53, no. 7, pp. 2267-2273, July 2005.

[5] K. Sarhadi and M. Shahabadi, "Wideband substrate integrated waveguide power splitter with high isolation," IET Microw. Antennas Propag., vol. 4, no. 7, pp. 817-821, 2010.

[6] T. Djerafi, A. Patrovsky, K. Wu, S. O. Tatu, "Recombinant Waveguide Power Divider," IEEE Transactions on Microwave Theory and Techniques, vol. 61, no. 11, pp. 3884-3891, November 2013.

[7] E. Pucci, E. Rajo-Iglesias, J. L. Vazquez-Roy, and P. S. Kildal, "Planar Dual-Mode Horn Array With Corporate-Feed Network in Inverted Microstrip Gap Waveguide," IEEE Trans. Antennas Propag. , vol. 62, no. 6 , pp. 3534-3542, 2014.

[8] A. Razavi, P.-S. Kildal, X. Liangliang, E. Alfonso, and H. Chen, "2x2slot Element for $60 \mathrm{GHz}$ Planar Array Antenna Realized on Two Doubled-sided PCBs Using SIW Cavity and EBG-type Soft Surface fed by Microstrip-Ridge Gap Waveguide," IEEE Trans. Antennas Propag. , vol. 62, no. 9, pp. 4564-4573, Sep. 2014.

[9] A. U. Zaman and P. S. Kildal, "Wide-Band Slot Antenna Arrays With Single-Layer Corporate-Feed Network in Ridge Gap Waveguide Technology," IEEE Trans. Antennas Propag., vol. 62, no. 6, pp. 29923001, June 2014.

[10] B. Cao, H. Wang, and Y. Huang, "W-band High Gain TE $220-$ Mode Slot Antenna Array with Gap Waveguide Feeding Network," IEEE Trans. Antennas Propag, Early access, 2015.

[11] B. Cao, H. Wang, Y. Huang, and J. Zheng, "High-Gain L-Probe Excited Substrate Integrated Cavity Antenna Array with LTCC-based Gap Waveguide Feeding Network for W-band Application," IEEE Trans. Antennas Propag, Early access, 2015. 